\title{
Analysis of Electrical conductivity of Ground water at different locations of Phooli of U.P, India
}

\author{
Anita $^{1}$ and Salahuddin ${ }^{2}$ \\ 1: Department of Mathematics, Prarambh School for Teacher Education, Jhajjar, Haryana, \\ India
}

2: P.D.M University, Bahadurgarh, Haryana, India

Abstract

In this paper, we discuss about the recently collected sample of ground water at surrounding locations of Phooli. We represent the data graphically and interpreted the data using the method called analysis of variance. Further, we analyze our findings with the established results and concluded that electric conductivity depends on areas as well as months also.

Keywords: Analysis of variance, electric conductivity.

\subsection{Electric Conductivity}

Electrical conductivity (EC) is a measurement of the dissolved material in an aqueous solution, which relates to the ability of the material to conduct electrical current through it. EC is measured inunits called Seimens per unit area (e.g. $\mathrm{mS} / \mathrm{cm}$, or miliSeimens percentimeter), and the higher the dissolved material in a water or soil sample, the higher the EC will be in that material.

\subsection{Analysis of Variance [3, p.256-258]}

Analysis of variance (abbreviated as ANOVA) is an extremely useful technique concerning researches in the fields of economics, biology, education, psychology, sociology, business/industry and in researches of several other disciplines. This technique is used when multiple sample cases are involved. As stated earlier, the significance of the difference between the means of two samples can be judged through either $z$-test or the $t$-test, but the difficulty arises when we happen to examine the significance of the difference amongst more than two sample means at the same time. The ANOVA technique enables us to perform this simultaneous test and as such is considered to be an important tool of analysis in the hands of a researcher. Using this technique, one can draw inferences about whether the samples have been drawn from populations having the same mean.

The ANOVA technique is important in the context of all those situations where we want to compare more than two populations such as in comparing the yield of crop from several varieties of seeds, the gasoline mileage of four automobiles, the smoking habits of five groups of university students and so on. In such circumstances one generally does not want to consider all possible combinations of two populations at a time for that would require a great number of tests before we would be able to arrive at a decision. This would also consume lot of time and money, and even then certain relationships may be left unidentified (particularly the interaction effects). Therefore, one quite often utilizes the ANOVA technique and through it investigates the differences among the means of all the populations simultaneously.

\section{Study Area}

The PhooliTalukaSonwali village is situated in the Ghazipur district with district code number 195. Zamania is the subdistrict (tehsil / mandal), is a low-level administrative division of a district, of this village, having the sub district code is 00991. Zamania is the 
Community Development Block (C.D. Block) of this village with C.D. Block code number 0761. The gram panchayat for this village is Sonhaia. The district headquarters' name is Ghazipur and as per distance concern it is 20 kilometres from the PhooliTalukaSonwali village.

\section{Location map of the Study area}

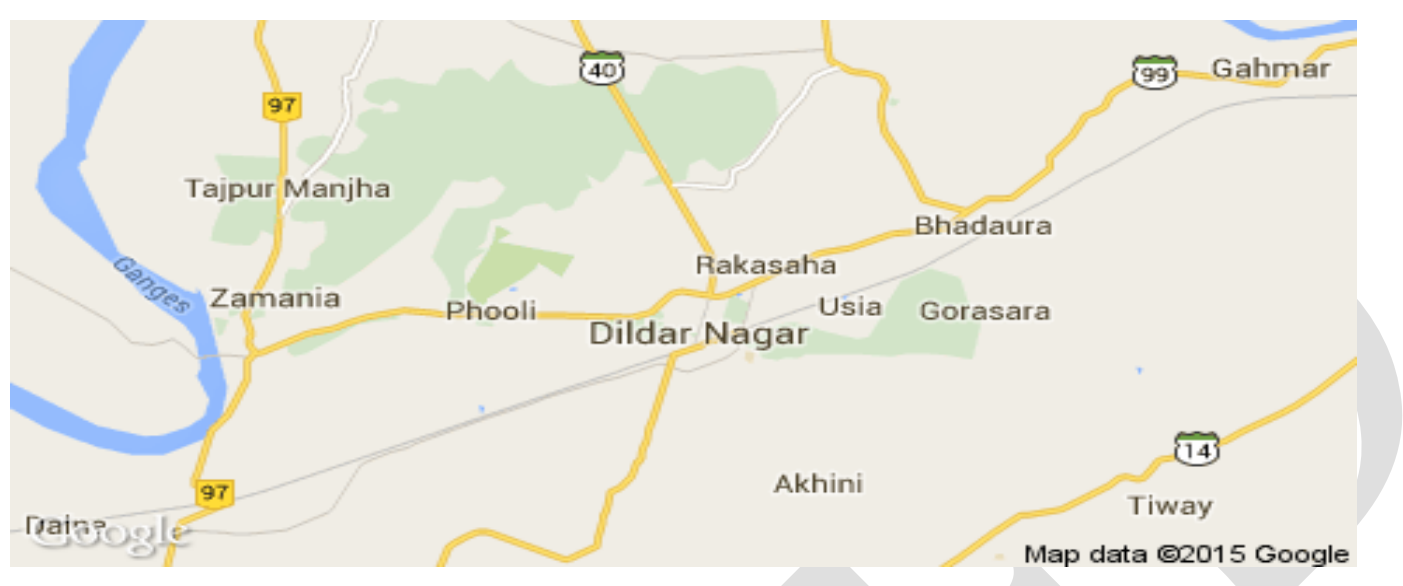

\section{MATERIALS AND METHODS}

\subsection{Sample Collection:}

The ground water samples were collected from different locations to evaluate the physicochemical contamination. Samples were collected in plastic container to avoid unpredictable changes in characteristic as per standard procedure (APHA, 1998). The results were compared with WHO standard values (2003). The details of sampling locations are illustrated below the Table1

Table 1: Water sampling locations and sources

\begin{tabular}{|c|l|l|}
\hline CODE & Sampling Station & Source \\
\hline GW1 & Gahmar & Bore well \\
\hline GW2 & Dildarnagar & Bore well \\
\hline GW3 & Rakasaha & Bore well \\
\hline GW4 & Nirahukapura & Bore well \\
\hline GW5 & Bhadura & Bore well \\
\hline GW6 & Gorsara & Bore well \\
\hline GW7 & Baksara & Bore well \\
\hline GW8 & Phooli & Bore well \\
\hline GW9 & Arangi & Bore well \\
\hline GW10 & Bhaksi & Bore well \\
\hline
\end{tabular}

\subsection{Instrument used:}

Electrical conductivity was measured using a meter and probe as well. The probe consists of two metal electrodes spaced $1 \mathrm{~cm}$ apart (thus the unit of measurement is microSeimens or milliSeimensper centimeter). A constant voltage was applied across the electrodes resulting in an electrical current flowing through the aqueous sample. 


\subsection{Measuring EC :}

1. Turn on the EC meter and calibrate the probe using a standard solution of known conductivity. Calibration procedures vary by instrument, so following the manufacturer's instructions is highly recommended. EC meters should be calibrated before each use (before each series of samples, not between each sample itself) or when measuring a large range of EC.

2. Check calibration by measuring the $\mathrm{EC}$ of the standard solutions in measure rather than calibrate mode.

3. Collect sample water in a glass or plastic container. Collect enough so the probe tip can be submerged in sample; either rinse the probe with deionised water (and blot dry) or with sample before inserting the probe into the collection vessel.

4. Submerge the probe into the sample and wait until the EC reading on the meter stabilizes. Many meters have automatic temperature correction (ATC), which calculates the EC taking into account temperature, if your meter does not have this feature, you may need to adjust a knob on the meter to correct the EC for temperature. Record the measurement when the EC reading is stable.

The experimental analysis of electric conductivity of sampling locations are illustrated below the table 2 and graphically represented in fig 1 and the statistical analysis of the data are illustrated in table 3 .

Table (2): Monthly variation in Electrical Conductivity $(\mu \mathrm{mho} / \mathrm{cm})$ of ground water at different sites

\begin{tabular}{|c|c|c|c|c|c|c|c|c|c|c|c|c|}
\hline CODE & JAN & FEB & MAR & APR & MAY & JUN & JUL & AUG & SEP & OCT & NOV & DEC \\
\hline GW1 & 361.7 & 354.0 & 345.2 & 355.9 & 356.8 & 364.5 & 373.2 & 352.6 & 376.5 & 382.1 & 353.0 & 342.9 \\
\hline GW2 & 333.1 & 345.2 & 336.1 & 331.0 & 341.0 & 336.2 & 336.0 & 327.0 & 337.9 & 347.4 & 333.4 & 355.9 \\
\hline GW3 & 462.0 & 473.7 & 435.9 & 429.1 & 393.6 & 382.9 & 435.4 & 444.5 & 483.0 & 476.7 & 457.6 & 467.8 \\
\hline GW4 & 182.8 & 183.0 & 157.9 & 165.0 & 153.2 & 165.9 & 154.5 & 178.3 & 186.3 & 191.2 & 194.2 & 196.4 \\
\hline GW5 & 349.9 & 335.2 & 347.1 & 327.1 & 310.0 & 305.9 & 291.9 & 297.8 & 329.7 & 321.1 & 349.2 & 364.3 \\
\hline GW6 & 281.6 & 282.5 & 234.4 & 241.6 & 248.0 & 244.3 & 236.2 & 221.2 & 246.1 & 244.2 & 243.6 & 252.7 \\
\hline GW7 & 183.6 & 168.4 & 149.2 & 164.5 & 147.0 & 170.6 & 184.7 & 176.1 & 193.1 & 211.2 & 181.4 & 178.5 \\
\hline GW8 & 321.0 & 337.0 & 346.0 & 325.5 & 292.9 & 280.2 & 294.9 & 322.1 & 326.7 & 319.7 & 339.2 & 330.6 \\
\hline GW9 & 163.2 & 163.1 & 175.0 & 171.6 & 161.0 & 152.8 & 164.6 & 178.2 & 154.1 & 162.4 & 154.8 & 161.0 \\
\hline GW10 & 183.2 & 169.7 & 178.9 & 192.9 & 163.5 & 188.7 & 157.9 & 187.0 & 164.0 & 156.7 & 146.3 & 168.4 \\
\hline
\end{tabular}

GW1= Gahmar, GW2 = Dildar Nagar, GW3 = Rakasaha, GW4 = Nirahukapura, GW5 = Bhadaura, GW6 = Gorsara, GW7 = Baksara, GW8 = Phooli, GW9 = Arangi, GW10 = Bhaksi

Fig 1: Graphical representation of electric Conductivity

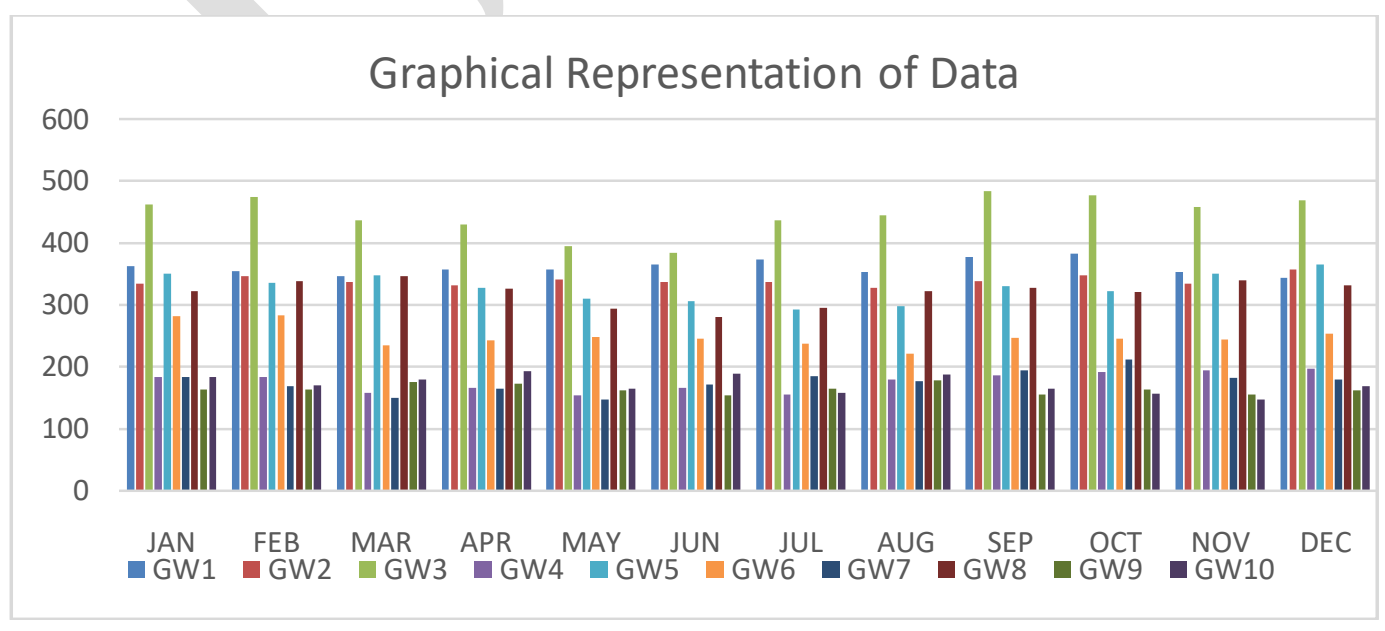

Table 3. Analysis the Data using two way Anova 


\begin{tabular}{lrrrr}
\hline SUMMARY & Count & \multicolumn{1}{c}{ Sum } & \multicolumn{1}{c}{ Average } & Variance \\
\hline GW1 & 12 & 4318.4 & 359.8667 & 148.7352 \\
GW2 & 12 & 4060.2 & 338.35 & 63.10636 \\
GW3 & 12 & 5342.2 & 445.1833 & 1015.107 \\
GW4 & 12 & 2108.7 & 175.725 & 246.9875 \\
GW5 & 12 & 3929.2 & 327.4333 & 521.6824 \\
GW6 & 12 & 2976.4 & 248.0333 & 315.9806 \\
GW7 & 12 & 2108.3 & 175.6917 & 316.1445 \\
GW8 & 12 & 3835.8 & 319.65 & 406.6936 \\
GW9 & 12 & 1961.8 & 163.4833 & 64.33242 \\
GW10 & 12 & 2057.2 & 171.4333 & 214.3442 \\
& & & & \\
JAN & 10 & 2822.1 & 282.21 & 10099.17 \\
FEB & 10 & 2811.8 & 281.18 & 11247.82 \\
MAR & 10 & 2705.7 & 270.57 & 10557.2 \\
APR & 10 & 2704.2 & 270.42 & 9037.811 \\
MAY & 10 & 2567 & 256.7 & 8965.133 \\
JUN & 10 & 2592 & 259.2 & 7556.527 \\
JUL & 10 & 2629.3 & 262.93 & 9821.947 \\
& & & & \\
AUG & 10 & 2684.8 & 268.48 & 8767.771 \\
SEP & 10 & 2797.4 & 279.74 & 11701.25 \\
OCT & 10 & 2812.7 & 281.27 & 11093.38 \\
NOV & 10 & 2752.7 & 275.27 & 11083.46 \\
DEC & 10 & 2818.5 & 281.85 & 11030.08 \\
\hline
\end{tabular}

\begin{tabular}{|c|c|c|c|c|c|c|}
\hline $\begin{array}{l}\text { Source of } \\
\text { Variation }\end{array}$ & $S S$ & $d f$ & $M S$ & $F$ & $P$-value & $F$ crit \\
\hline Rows & 1061574 & 9 & 117952.6 & 431.2075 & $3.06 \mathrm{E}-75$ & 1.975806 \\
\hline Columns & 9363.763 & 11 & 851.2512 & 3.111977 & 0.001234 & 1.886684 \\
\hline Error & 27080.49 & 99 & 273.5403 & & & \\
\hline Total & 1098018 & 119 & & & & \\
\hline
\end{tabular}

\subsection{Results and Discussion:}

The data is statistically analysed using two-way analysis of variance and after analysis the result shows that electrical conductivity of ground water of these areas depends on locations as well as months also that is in different area electric conductivities are different and it changes according to months also.

\section{References}

[1]. Andrew Gelman, Analysis of variance? Why it is more important than ever, The Annals of Statistics 33: 1-53, 2005. 
[2]. Aitken, Alexander Craig, Statistical Mathematics 8th Edition. Oliver \& Boyd, 1957.

[3] C. R.Kothari;Research Methodology, New Age International (P) Limited, Publishers, New Delhi, 2004.

[4]. David A Freedman, Statistical Models: Theory and Practice, Cambridge University Press, 2005.

[5]. D. R.Cox, Principles of statistical inference. Cambridge New York: Cambridge University Press, 2006.

[6].F. J. Anscombe, The Validity of Comparative Experiments,Journal of the Royal Statistical Society. Series A (General) ,181-211, 1948.

[7]. Henry Scheffé, The Analysis of Variance. New York: Wiley, 1959.

[8].Jacob Cohen, Statistics a power primer". Psychology Bulletin 112: 155-159, 1992.

[9].William G. Cochran, Gertrude M. Cox, Experimental designs (2nd ed.). New York: Wiley, 1992.

[10]Y. K.Singh;Fundamental of Research Methodology and Statistics, New Age International (P) Limited, Publishers, New Delhi, 2006. 